\title{
EXPERIMENTAL STUDY OF HEAT TRANSFER IN THE STEAM THERMAL SIPHON TUBE CHANNEL
}

\author{
Mikhail A. Ulchiekov, ${ }^{1, *}$ \\ ${ }^{1}$ National research Tomsk Polytechnic University, Tomsk 634050, Russia
}

\begin{abstract}
The results of experimental studies of heat transfer into the thermo-syphon tube with different thermal loads are represented. Are examined two types of liquid as the working fluid. The values of temperatures in the steam channel of thermo-syphon tube are registered and the dependences of the coefficients of heat exchange on the power of heating element are obtained. The influence of thermal load and properties of liquid on the intensity of the processes of evaporation and condensation of working fluid in the thermo-syphon installation are established.
\end{abstract}

\section{Introduction}

In connection with the development of electronic technology and the decrease of sizes of typical articles appears the need for devices for the intensive outlet of heat.

Due to the development of electronic technology and decrease of typical articles sizes appears the need for devices for intensive heat removal. These can be thermosiphon tube [1-3]. But the use of thermosiphons is not limited only to cooling devices of electronic engineering. They are effective with the industrial heat recovery, blade cooling of turbines, in the heating systems, etc [4]. A main difference in the thermo-syphon from the usual thermal tube in the fact that in the thermosiphon is used gravity, but not the force of surface tension for the recovery of condensate into the zone of the evaporation [5-6]. Studies in this area much [1-6], but little experimental data $[1,5]$, in connection with which this problem is urgent.

Purpose of the work - an experimental study of heat exchange in the thermo-syphon tube over a wide range of a change in the heat flux of applied into the boiling zone on lower boundary of steam channel.

The subject of a study is glass thermo-syphon tube lower surface of which it is located on the heating element. As the working fluids were investigated water and ethyl alcohol with the space factors of steam channel from 0.1 to 0.4 .

* Corresponding author: ulchieckovmihail@mail.ru 


\section{Methods of experimental research}

Experimental installation consisted of the glass tube (external de $=0.04 \mathrm{~m}$, internal $\mathrm{di}=0.038$ $\mathrm{m}$ diameters, height $\mathrm{l}=0.28 \mathrm{~m}$.), closed on top, heating element, autotransformer, multichannel device for measuring the temperature, connected to the computer through the adapter, heat insulation.

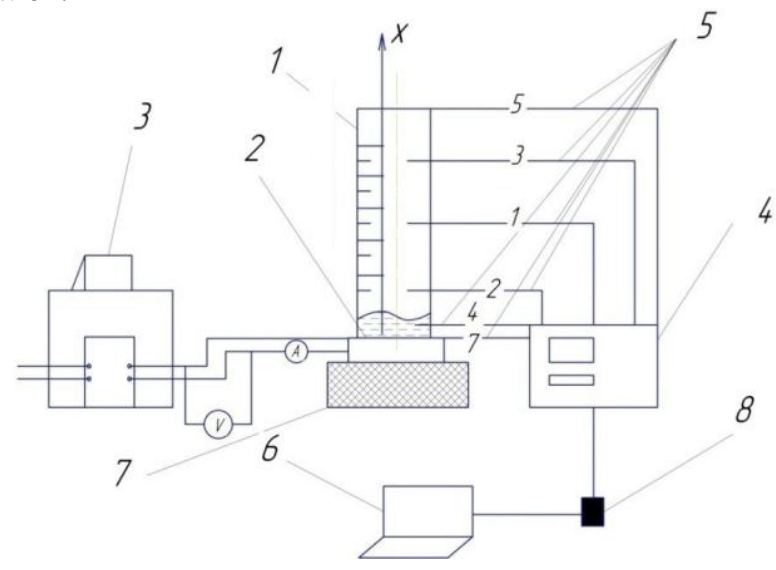

Fig. 1. Schematic diagram of installation: 1 - thermal siphon tube; 2 - a heating element; 3 - autotransformer; 4 - Temperature-measuring device UKT38, 5 - thermocouple, 6 - a computer; 7 - thermal insulation; 8 - Adapter.

Temperature measurements were carried out using a chromel-alumel thermocouples are connected to the multi-channel measuring device OWEN UKT 38 as in [7, 8]. The values of the temperature every 2 seconds recorded on a personal computer software National Instruments LabView 8.1. Location of thermocouples in the thermosyphon are shown in table, where n-number entry into multi-channel measurement device:

Table 1. Location of thermocouples.

\begin{tabular}{|c|c|c|c|c|c|c|}
\hline $\mathrm{n}$ & 1 & 2 & 3 & 4 & 5 & 7 \\
\hline $\mathrm{h}, \mathrm{mm}$ & 140 & 70 & 210 & 1 & $\begin{array}{c}\text { the top } \\
\text { cover }\end{array}$ & heater \\
\hline
\end{tabular}

The heating element is a tungsten wire, laid in a flexible hollow channel of the thermal insulation material. On the wire is put electrical insulator layer and a thin aluminum plate with a diameter $0.04 \mathrm{~m}$. and a thickness $0.002 \mathrm{~m}$.

Regulator power heater - autotransformer connected to the AC frequency of $50 \mathrm{~Hz}$ and a voltage of $220 \mathrm{~V}$. In order to register the output voltage and current used by digital multimeter M266 series with contactless current sensor (accuracy class 0.1 ).

In the voltage regulator, which is connected to the heater, and the measured voltage exhibited a multimeter. Heater power ranged from 10 watts to 30 watts.

A metering device $3 \mathrm{ml}$ were pumped liquid (alcohol or water) in the thermosyphon with thermocouples. The experiment is complete when the temperature of the tube height did not change over time (stationary mode). 


\section{Results and discussion}

Fig. 2 shows the results of an experimental study of the heat transfer process in the steam thermal siphon tube channel (operating fluid - water):
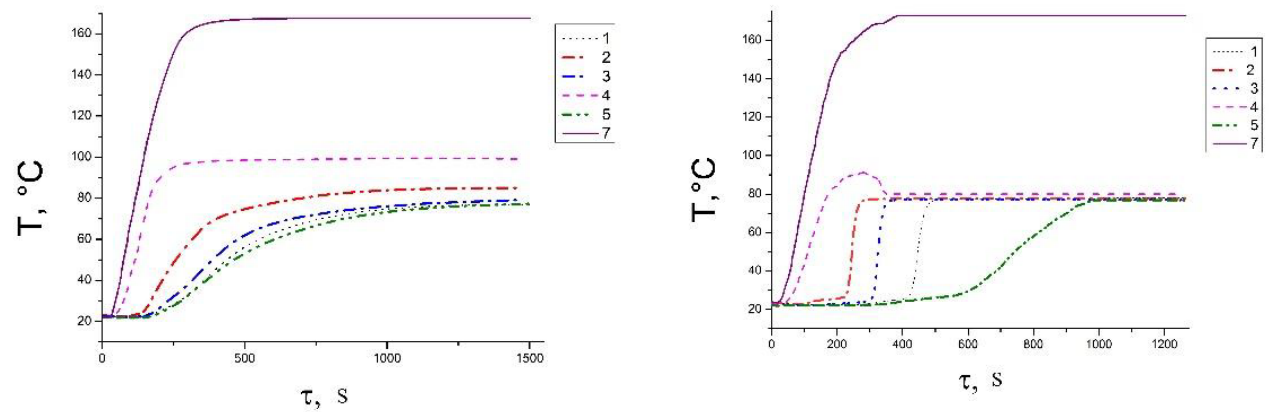

Fig. 2. The temperatures at different points of the thermosyphon, depending on the time when the power of the heating element $\mathrm{q}=12 \mathrm{~kW} / \mathrm{m} 2$ : a) water; $b$ ) alcohol.

After the switching on heater the liquid temperature began gradually to grow to the boiling point (temperature of alcohol it rose above the boiling point, after which it occurred sharp effervescence and a decrease to the boiling point). The value of the temperature of heating element rose to the moment of intensive vaporization. An increase in temperatures on the height of thermosiphon began after effervescence and continued to the specific values (in this case in alcohol it was observed an uneven increase in the temperature on the height of tube).

Fig. 3 shows the dependence of the boiling and condensing the working fluid from the fuel cell power. The procedure was used [9]:

$$
\alpha_{\text {boil }}=N u_{*} \cdot \frac{\lambda}{l_{*}}, \alpha_{\text {cond }}=\frac{G \cdot r}{\pi \cdot d_{\text {in }} \cdot l \cdot\left(t_{S K}-t_{C}\right)},
$$

here $\alpha_{b o i l}, \alpha_{c o n d}$ - heat transfer coefficients during condensation and boiling, respectively, $\mathrm{W} / \mathrm{m}^{2} \cdot \mathrm{K} ; \quad N u_{*}$ - Nusselt number, depends on boiling regime [9]; $\lambda-$ the coefficient of thermal conductivity of the boiling liquid, W/mK; $l_{*}$ - reduced size, $\mathrm{m}$ [9]; $G$ - steam flow, $\mathrm{kg} / \mathrm{s} ; r$ - heat of vaporization, $\mathrm{J} / \mathrm{kg} ; d_{i n}, l$ - the inner diameter of the steam passage length, $\mathrm{m} ; t_{s k}, t_{c}$ - temperature of steam and the condensation surface, $\mathrm{K}$. The steam consumption amounted condensate flow, since the calculation was performed for the steady state.

Is established (fig. 3), that the heat load on the thermosyphon growth leads to a proportional increase (linearly) the heat transfers coefficient of condensing fluid. Due to differences between the thermal and hydrodynamic parameters of the heat transfer coefficient of condensing an alcohol vapor is higher than that of water at $150 \mathrm{~W} /\left(\mathrm{m}^{2} \cdot \mathrm{K}\right)$ in the whole range of the thermal load on evaporation below $90 \mathrm{~W} /\left(\mathrm{m}^{2} \cdot \mathrm{K}\right)$. Since ethanol is more volatile than water, the flow of alcohol vapor during the boiling is more. Since ethyl alcohol is more volatile component than water, then the expenditure of vapors of alcohol during the boiling is more.

Therefore, for the efficient operation of thermosiphon systems use low-boiling liquids as working medium is preferable from the standpoint of the efficiency of such heat exchangers. 


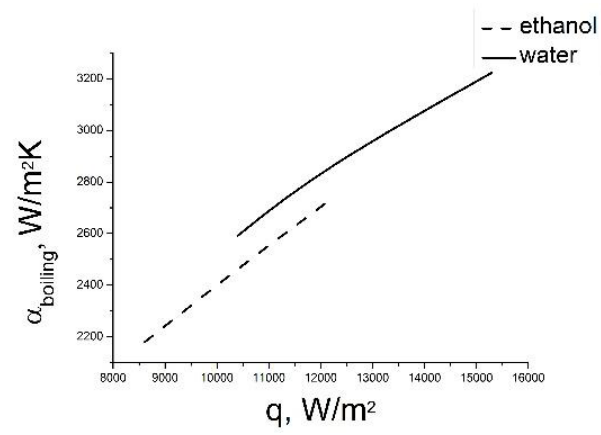

a)

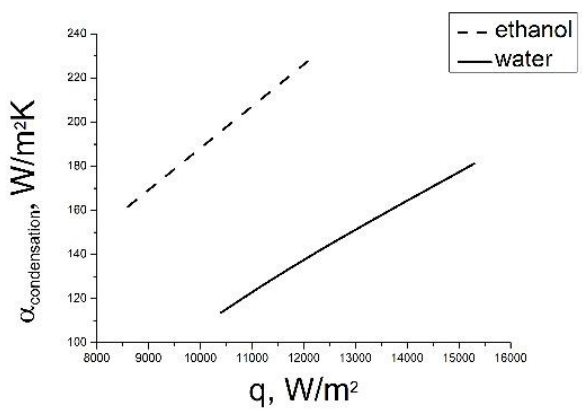

b)

Fig. 3. Dependencies heat transfer coefficient with: a) boiling ( 1 - water 2 - alcohol); b) condensation (1 - water 2 - alcohol).

\section{Conclusion}

Are experimentally obtained the temperature fields in the thermo-syphon installation with different modes of its operation. Are obtained the dependences of the heat-transfer coefficients of working medium during its boiling and condensation in the thermosiphon with a change in the thermal load and the use of different working fluids. As a result, an experimental study it is established that with an increase in the thermal load the condensing coefficient and boiling of water and alcohol increases practically in the linear law. It is also established that the use of the low-boiling-point liquid in the thermo-syphon installation leads to the intensification of the process of heat transfer in the steam channel of thermosyphon tube. Obtained in the work experimental data and dependences can be used both for the design of new thermo-syphon installations and modernization of the already working heat exchange equipment.

\section{Acknowledgments}

The work at the field of modeling of heat and mass transfer processes near boundary between two layers was supported by the scientific schools grant NSH-7538-2016.8.

\section{References}

1. Seok-Ho Rhi, An Experimental and Analytical Study on Two-Phase Loop Thermosyphons (Canada, 2000)

2. G.V. Kuznetsov, M.A. Al-Ani, M.A. Sheremet, J. Eng. Thermoph. 20 (2011)

3. J.G. Reed, C.L. Tien, ASME. J. Heat Trans. 109 (1987)

4. Kh. Kafeel, A. Turan., Heat Mass Trans. 49 (2013)

5. H. Farsi, J.-L. Joly, M. Miscevic, V. Platel, N. Mazet, Appl. Th. Eng. 23 (2003)

6. G.V. Kuznetsov, A.E. Sitnikov, High Temp. 40 (2002)

7. A.S., Krasnoshlykov, V.I. Maksimov, MATEC Web Conf. 19 (2014)

8. G.V. Kuznetsov, V.I. Maksimov, M.A. Sheremet, J. of Appl. Mech. Tech. Ph. 54 (2013)

9. S.S. Kutateladze, Heat Transfer in Condensation and Boiling (Mashgiz, Moscow, 1952) 